\title{
Educação e Cultura para a Democracia em Darcy Ribeiro
}

\author{
Libânia Nacif Xavier - Universidade Federal do Rio de Janeiro (UFRJ)
}

\begin{abstract}
Resumo: O artigo analisa a participação de Darcy Ribeiro na criação de instituições, bem como na implantação de políticas inovadoras no âmbito da educação e da cultura brasileiras. Está dividido em cinco seções: a primeira analisa a trajetória de Darcy Ribeiro, destacando sua atuação no âmbito da educação. A segunda e a terceira se referem aos projetos com os quais se envolveu sempre em contextos democráticos, exercendo uma intervenção bem específica na organização do ensino; a quarta aborda as ideias que ele apresentou como eixos orientadores de sua ação política e de seu posicionamento intelectual, em especial durante o período em que atuou como Senador da República (1991-1997). A quinta e última parte analisa o padrão de conduta política e intelectual adotado por Darcy Ribeiro em suas intervenções na educação pública, no âmbito executivo ou legislativo.
\end{abstract}

Palavras-chave: Darcy Ribeiro; história da educação no Rio de Janeiro.

\section{Education for Culture and Democracy in Darcy Ribeiro}

\begin{abstract}
The article analyzes the participation of Darcy Ribeiro in the creation of institutions, as well as in the implementation of innovative policies in the scope of Brazilian education and culture. It is divided into five sections: the first one analyzes the trajectory of Darcy Ribeiro, highlighting his experience in education. The second and third refer to the projects with which he was involved always in democratic contexts, exerting a very specific intervention in the organization of teaching. The fourth part deals with the ideas he presented as the guiding principles of his political action and intellectual position, especially during the period in which he served as Senator of the Republic (1991-1997). The fifth and final part analyzes the pattern of political and intellectual conduct adopted by Darcy Ribeiro in his interventions in public education, whether in the executive or legislative sphere.
\end{abstract}

Key-words: Darcy Ribeiro; educational history in Rio de Janeiro.

\section{Educação e Cultura para a Democracia em Darcy Ribeiro}

O estudo analisa a participação de Darcy Ribeiro na criação de instituições, bem como na implantação de políticas inovadoras no âmbito da educação e da cultura brasileiras. Sua trajetória, como intelectual e homem público, expõe os avanços e retrocessos decorrentes dos embates entre forças políticas conservadoras e democráticas. Seu espírito crítico e criativo, aliado a um modo de agir, não raro, apressado (GOMES, 2010) e indisciplinado (BOMENY, 2001), expressam em 
que medida a ciência e a política, postas uma a serviço da outra, constituíram vetores de tensão, mas, também, de harmonização da trajetória multifacetada -- de antropólogo, educador, ensaísta e homem público - traçada por este indivíduo singular (Heymann, 2012).

O objetivo central do presente estudo será identificar o padrão de ação política e de dimensionamento intelectual que estruturaram a atuação de Darcy Ribeiro no campo da educação. Pretendemos, ainda, identificar o que esse padrão de conduta social, de ação prática e de comportamento político nos informa a respeito do campo de possibilidades que permeia a organização do ensino brasileiro, no âmbito legislativo e executivo, bem como no seu aspecto intelectual.

Para tanto, dividiremos este artigo em cinco seções. A primeira analisa a trajetória de Darcy Ribeiro, destacando sua atuação no âmbito da educação. A segunda e a terceira se referem aos diferentes projetos com os quais ele se envolveu, sempre em contextos democráticos, exercendo uma intervenção bem específica na organização do ensino. A quarta, aborda as ideias que ele apresentou como eixos orientadores de sua ação politica e de seu posicionamento intelectual, em especial durante o período em que atuou como Senador da República (1991-1997). Para tanto, tomaremos como base os escritos publicados na Revista Carta, falas, reflexões e memórias, que funcionou como veículo de difusão de ideias, informação e esclarecimentos, editada por ele e por sua equipe, ao longo de seu mandato. A quinta e última parte analisa o padrão de conduta política e intelectual adotado por Darcy Ribeiro em suas intervenções na educação pública, seja no âmbito executivo ou legislativo. Interessa-nos, também, analisar os termos nos quais ele procurou disseminar uma interpretação a respeito dos problemas nacionais, da constituição do povo brasileiro e de seus traços culturais particulares, além da própria construção de uma memória da educação que se confunde com sua própria trajetória.

\section{Uma trajetória marcada pelas oscilações da democracia brasileira}

A trajetória de Darcy Ribeiro expõe o seu envolvimento em várias áreas de atuação. Nas ciências sociais, ele é considerado um precursor da etnologia brasileira, tendo sido, também, um militante em defesa das populações indígenas. Na educação, ele abraçou a luta pela universalização da educação publica popular e pela reestruturação do ensino superior, exercendo, ainda, importante papel na formação de novos cientistas sociais. Como homem público, assumiu cargos oficiais, envolveu-se em campanhas e movimentos que, segundo o repertório dos anos 1950-60, visavam a superação do nosso atraso econômico e de nossa dependência cultural.

Mineiro de Montes Claros (MG), Darcy nasceu em 26 de novembro de 1922. Na juventude, se filiou ao Partido Comunista e cursou a Escola de Sociologia e Política da Universidade de São 
Paulo (USP). Concluiu o curso em 1946, um ano após a queda do Estado Novo e toda a movimentação que marcou o processo de redemocratização do país. ${ }^{1}$ Nesse mesmo ano foi contratado pelo Serviço de Proteção ao Índio (SPI), onde passou a trabalhar como etnólogo, função que o levou a viver cerca de dez anos junto a comunidades indígenas no interior da Amazônia. Nos anos 1950, ele atuou ao lado do educador Anísio Teixeira, no Centro Brasileiro de Pesquisas Educacionais (CBPE), coordenando pesquisas e formando cientistas sociais, ao mesmo tempo em que se envolveu nos embates pela educação pública, conforme detalharemos adiante.

\section{Anos 1950-60: da questão indígena para a educação popular}

Durante a década de 1950, Darcy Ribeiro participou do Programa de Pesquisa sobre Relações Raciais no Brasil, promovido pela Organização das Nações Unidas para a Educação, a Ciência e a Cultura (Unesco), desenvolvendo a análise do processo de assimilação dos índios na sociedade brasileira. Em 1952 assumiu a direção da Seção de Estudos do SPI, onde deu início aos trabalhos para a organização do Museu do Índio. Ainda em sua passagem no SPI, participou, juntamente com Noel Nutels e Eduardo Galvão, da formulação do projeto de criação do Parque Indígena do Xingu, implantado anos mais tarde sob a direção dos irmãos indigenistas Cláudio e Orlando Vilas Boas. Ainda na direção da Seção de Estudos do SPI, Darcy organizou um curso de pós-graduação para formar pesquisadores em sociologia e antropologia.

Com a eleição de Juscelino Kubitscheck (JK) para a presidência da República, em outubro de 1955, foi convidado, juntamente com o educador Anísio Teixeira, para colaborar na elaboração das diretrizes para o setor educacional do novo governo. Em 1956, desincompatibilizou-se de suas funções no SPI, ingressando, em seguida, na Faculdade Nacional de Filosofia da Universidade do Brasil, no Rio de Janeiro, como professor das cadeiras de Etnologia Brasileira e Tupi-Guarani.

No ano seguinte, assumiu a coordenação da Divisão de Estudos e Pesquisas Sociais do Centro Brasileiro de Pesquisas Educacionais (CBPE), órgão ligado ao Instituto Nacional de Estudos Pedagógicos do Ministério da Educação. Dirigido por Anísio Teixeira, o Centro visava reunir e formar quadros qualificados para interferir na educação pública brasileira de modo racional e planejado. Lá, ele deu seguimento ao curso de formação de pesquisadores em antropologia e coordenou o Programa de Pesquisas em Cidades Laboratório, por meio do qual orientou cerca de 30 pesquisas sócio-antropológicas voltadas para a análise das relações entre urbanização, industrialização, família e educação. Sob sua orientação, o Centro passou a publicar a Revista de Educação e Ciências Sociais, que circulou desde o ano de 1956 até 1962 (XAVIER, 2008). 
Darcy Ribeiro teve atuação destacada no processo de tramitação da Lei de Diretrizes e Bases da Educação Nacional - LDBEN (1948-1961), juntando-se aos intelectuais que propugnavam uma educação pública, leiga, universal e gratuita, sob responsabilidade do Estado. Frente aos ataques dirigidos ao projeto defendido pelo grupo, ele redigiu um manifesto em defesa do educador Anísio Teixeira, intitulado Por uma Escola Primária Organizada e Séria pra a Formação Básica do Povo Brasileiro, publicado no ano de 1958, em dezenas de jornais. ${ }^{2} \mathrm{O}$ episódio revela uma espécie de conversão do etnólogo que, conforme ele próprio observara posteriormente, até então se preocupara apenas com os índios e gradativamente despertava para a importância de incluir em suas preocupações os milhares de crianças brasileiras sem acesso à escola e aos direitos básicos de cidadania (RIBEIRO:1986, pág.216).

Abraçando a bandeira da educação, Darcy Ribeiro reagiu às investidas de grupos que defendiam o amparo financeiro do Estado às escolas particulares, tal como proposto no substitutivo ao projeto de Lei apresentado em 1958, pelo deputado udenista e candidato ao governo do estado da Guanabara, Carlos Lacerda. Condenando publicamente o substitutivo Lacerda, Darcy alertou que por trás da defesa dos direitos da família e da oposição ao ensino público, a verdadeira disputa se dava em torno das dotações orçamentárias. Mais tarde, ao relembrar aqueles conflitos, ele valorizou o movimento em defesa da escola pública pela possibilidade que abriu a um grande número de intelectuais universitários de encontrarem uma via de acesso à militância em prol da democratização da sociedade brasileira.

Em julho de 1960, um decreto do Governo nomeou Darcy Ribeiro presidente da Comissão encarregada de projetar a Universidade de Brasília (UnB). Com base no diagnóstico de que a universidade brasileira passava por uma crise, fruto da manutenção de um modelo obsoleto de organização do ensino superior, considerado insuficiente para atender às necessidades nacionais, a UnB foi apresentada como o modelo ideal de universidade, por buscar ser criadora de uma cultura nacional de base cientifica e formadora de mestres capazes de reformular e difundir a cultura nacional (RIBEIRO, 1970:122).

Segundo o próprio Darcy, a concepção da UnB contemplava várias ambições: Em primeiro lugar, a ambição de plantar uma universidade no centro político e administrativo do país, capaz de conviver com os tradicionais centros de produção cultural, nacionais e estrangeiros, atendendo criativamente aos desafios do desenvolvimento do Brasil. A segunda ambição foi a de proporcionar aos órgãos públicos a (re) produção de quadros intelectuais de alto nível aptos a prestar assessoria em uma cidade isolada e, a terceira ambição era fazer da UnB um núcleo de amadurecimento da consciência crítica nacional, privilegiando programas de estudo mais capazes de instrumentá-la cientificamente e de sustentá-la ideologicamente. Para Darcy, esta Revista Interinstitucional Artes de Educar. Rio de Janeiro, V. 3 N.2 - pag 31- 46 (jul/out2017): "Número Esperial Darcy Ribeiro" DOI: $10.12957 /$ riae.2017.31709 


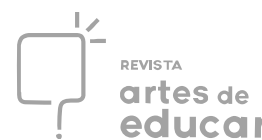

terceira ambição vinha acompanhada do desafio de articular a intelectualidade oficial e, sobretudo a acadêmica, na tarefa de repensar o Brasil enquanto projeto, buscando novas formas de organização com vistas à superação do subdesenvolvimento. Cabia, ainda, institucionalizar a pósgraduação como atividade regular de pesquisa e formação, de modo a permitir que a nova capital exercesse efetivamente o papel de um centro de expressão da consciência crítica nacional (RIBEIRO, 1970, 64-68).

Brasília foi inaugurada no dia 21 de abril de 1960 e em janeiro de 1961 JK transferiu a chefia do governo a Jânio Quadros. Na mesma época foram inaugurados os cursos da UnB. Darcy foi nomeado seu primeiro reitor, permanecendo no cargo até agosto de 1962, sendo sucedido por Anísio Teixeira. Em seguida, assumiu a chefia do Ministério da Educação e Cultura, a convite do presidente João Goulart. Como ministro da Educação, ele criou o Fundo Nacional de Ensino, determinando a aplicação de $12 \%$ da receita da União para o aperfeiçoamento e desenvolvimento da educação pública, o que, embora constitucionalmente previsto, só ocorreu de fato durante sua gestão.

No ano seguinte, por ocasião do retorno ao regime presidencialista, Darcy Ribeiro deixou o Ministério para assumir o cargo de chefe do Gabinete Civil da Presidência da República. Porém, como desfecho da crise política instaurada após o Comício da Central do Brasil, no qual o Presidente João Goulart reafirmou seu propósito de implantar as reformas de base -- que incluíam a reforma agrária, administrativa, bancária e fiscal -- eclodiu o movimento político-militar que resultou na deposição do presidente da República. Tendo se colocado ao lado do Presidente deposto, Darcy teve que deixar o Gabinete Civil, exilando-se no Uruguai. Em decorrência, foi destituído de seus direitos políticos pelo Ato Institucional n ${ }^{\circ} 1$ (AI-1), editado pelo Comando Supremo daquele movimento.

No Uruguai, lecionou antropologia na Universidade de Montevidéu, onde também desenvolveu uma série de trabalhos relacionados com o sistema universitário, como o Seminário sobre as Estruturas Universitárias que resultou na publicação do livro Universidade Necessária, em 1967. Em outubro de 1968 retornou ao Brasil, em meio ao acirramento do conflito entre Governo e oposição, que culminou com a edição do AI-5.

Logo em seguida à edição do ato, foi preso e indiciado num processo de infração à Lei de Segurança Nacional. No ano seguinte, foi julgado e absolvido pela Auditoria da Marinha do Rio de Janeiro, viajando em seguida para a Venezuela, onde lecionou e organizou o projeto de reforma da Universidade Nacional daquele país. Após dois anos, transferiu-se para o Chile, a convite do Presidente Salvador Allende, para assessorá-lo na chefia do governo socialista da Unidade Popular, lá permanecendo até 1973. Deixando o Chile, mudou-se para o Peru, onde liderou o 
planejamento de um sistema de universidade global para o governo peruano, elaborando, posteriormente, alguns estudos para universidades do México e da Costa Rica. ${ }^{3}$

\section{Anos 1980-90: ações nas esferas executiva e legislativa}

Em 1974, vítima de câncer pulmonar, voltou ao Brasil, onde foi submetido a uma intervenção cirúrgica, aqui permanecendo por apenas seis meses, tempo necessário para restabelecer-se. Retornou definitivamente ao Brasil em 1978. Nesse mesmo ano, foi reintegrado à Universidade Federal do Rio de Janeiro, onde assumiu o cargo de diretor-adjunto do Programa de Pós-Graduação em Ciências Sociais. Porém, em diversas entrevistas, Darcy expressou insatisfação com a vida acadêmica e, em particular com o campo da antropologia, na altura, bem mais especializada e institucionalizada que no tempo em que ele iniciou a sua carreira.

Com a abertura democrática, Darcy candidatou-se a vice-governador do Rio de Janeiro, na chapa encabeçada por Leonel Brizola na legenda do Partido Democrático Trabalhista (PDT), saindo vitorioso nas eleições realizadas em novembro de 1982. No Governo, ele ocupou o cargo de Secretário de Cultura, participando, também, da Comissão que elaborou o Programa Especial de Educação (PEE). O Programa previa a implantação das escolas de tempo integral — os chamados Centros Integrados de Educação Pública (Cieps) — onde o processo educativo não se limitava ao aprendizado dos conteúdos escolares formais, abrangendo a formação integral dos alunos, promovendo o seu desenvolvimento intelectual, artístico e social. Apesar da grande polêmica que o PEE mobilizou à época, é relevante destacar a concepção expressa por Darcy, sobretudo na imprensa, de que os Cieps deveriam funcionar como uma escola de ricos destinada às crianças pobres. Ampliando a perspectiva de adaptar a educação formal às necessidades e potencialidades das crianças dos setores populares, o PEE expressou a meta de promover a democratização do acesso à educação escolar, figurando como prioridade no Programa de Governo.

Em 1990, foi eleito Senador pelo estado do Rio de Janeiro, no mesmo pleito que elegeu Leonel Brizola ao Governo do estado. Durante o segundo Governo de Leonel Brizola (1991-1994), Darcy Ribeiro licenciou-se do Senado para assumir a Secretaria de Projetos Especiais de Educação do Governo, coordenando a retomada do PEE, que havia sido interrompido pela administração anterior. Durante sua gestão, concorreu para que fossem construídos mais algumas centenas de Cieps no estado e deu início a implantação dos Ginásios Públicos. No que tange ao ensino superior, destaca-se a criação da Universidade Estadual do Norte Fluminense (UENF) no município de Campos dos Goytacazes. ${ }^{4}$ 
Em 1992, ele retornou ao Senado, colocando-se em posição privilegiada para interferir no processo de tramitação de uma nova Lei para a Educação. Desta vez, a vanguarda do processo coube ao Fórum Nacional de Educação na Constituinte em Defesa do Ensino Público e Gratuito (FORUM), entidade que encaminhou à Subcomissão de Educação, Cultura e Desporto, numa proposta única, reivindicações de diversas entidades da sociedade civil, tais como a Associação Nacional de Pós-Graduação e Pesquisa em Educação (Anped), Central Geral dos Trabalhadores (CGT), Central Única dos Trabalhadores (CUT), Ordem dos Advogados do Brasil (OAB), Sociedade Brasileira para o Progresso da Ciência (SBPC) e União Nacional dos Estudantes (UNE), dentre outras. O primeiro substitutivo ao projeto, elaborado com a participação do fórum, foi aprovado pela Comissão de Educação no segundo semestre de 1990 e após dois anos de espera e debates, obteve aprovação no plenário da Câmara. No entanto, foram apresentadas 1.275 emendas em torno das quais se processou nova rodada de negociações, inaugurando um processo marcado por disputas, contradições e muitas protelações. Em fevereiro de 1993, a apresentação de um novo projeto de LDB por Darcy Ribeiro e sua rápida aprovação pela Comissão de Educação do Senado dividiu os partidos e as entidades aglutinadas no FORUM.

O novo projeto estabelecia um eixo orientador diferente do anterior, sobretudo no que dizia respeito à diminuição das responsabilidades do Estado para com educação, na medida em que só o ensino fundamental (e não toda a educação básica) era considerado obrigatório e gratuito. Porém, mesmo sob a oposição do FORUM, o substitutivo foi aprovado pela Câmara e, em seguida, sancionado pelo presidente Fernando Henrique Cardoso, consubstanciando a Lei $\mathrm{n}^{\circ}$ 9.349, conhecida como Lei Darcy Ribeiro. A justificativa do Governo para a aprovação daquele projeto de apenas 92 artigos foi a mesma defendida por Darcy Ribeiro, qual seja a de que a LDB deveria ser uma lei passível de cumprimento a partir dos recursos financeiros disponíveis nos esquemas orçamentários convencionais, devendo, ainda, apresentar flexibilidade para se adequar às diferentes situações da educação nacional.

Apesar de ter sido criticada -- tanto por seu conteúdo quanto pela forma unilateral como foi superposta no processo regular de tramitação -- a LDB manteve várias indicações do FORUM, simplificando algumas diretrizes e acrescentando outras. Cabe registrar que muitos de seus artigos se remetem a bandeiras pelas quais Darcy lutou ao longo de sua vida pública. Assim, a defesa da escola de tempo integral se faz presente no artigo 87, que aponta o compromisso de conjugar todos os esforços, objetivando a progressão das redes escolares públicas urbanas de ensino fundamental para o regime de escolas de tempo integral. Além disso, a Lei modificou as regras de acesso ao ensino superior, estabelecendo, ao lado do vestibular de caráter classificatório, a possibilidade de incorporação de alunos à universidade por meio de avaliações promovidas ao longo do ensino Revista Interinstitucional Artes de Educar. Rio de Janeiro, V. 3 N.2 - pag 31- 46 (jul/out2017): "Número Esperial Darcy Ribeiro" DOI: $10.12957 /$ riae.2017.31709 
médio. A lei criou também novas modalidades de instituições de ensino superior, como os centros universitários e as universidades especializadas por campo de saber, bem como a possibilidade do estudante se diplomar em cursos regulares via ensino a distância (através de TV, rádio ou Internet, por exemplo), o que até aquele momento não era previsto em qualquer legislação. Outra novidade foi a oferta de educação escolar bilíngue e intercultural aos povos indígenas com o objetivo de promover a recuperação de suas memórias históricas; a reafirmação de suas identidades étnicas, a valorização de suas línguas e ciências (...) (artigo 78).

Em 1997, Darcy publicou o seu último livro, Confissões, de caráter autobiográfico. Esse foi, também, o ano de seu falecimento.

\section{A trajetória do indivíduo e a história do país}

Apesar da grande quantidade de teses e dissertações sobre Darcy Ribeiro, torna-se difícil realizar um trabalho de análise da sua contribuição que não reproduza a monumentalização de sua trajetória, que ele próprio se preocupou em promover, assim como não é tarefa fácil evitar o estranhamento a respeito de sua personalidade impetuosa, seja no que tange as interpretações que tece sobre a história do país e de seus atores, seja o que e como ele fala de suas próprias realizações.

Seu percurso biográfico demonstra a preferência pelas condutas intempestivas, pelos rompantes inesperados, por projetos considerados utópicos, não raro apresentados como promessas de salvação nacional ${ }^{5}$. As observações de estudiosos de sua contribuição, tais como Bomeny (2001), Gomes, (2011) e Heymann, (2012), assim como sua própria autobiografia, registrada no livro Confissões (1997) confirmam, por meio de análises sobre diferentes aspectos de sua trajetória intelectual e de homem público, a diversidade e variedade de frentes nas quais ele atuou, tendo em vista o aprofundamento da democracia no país.

Nesse caminho, ele procurou articular a sua formação como cientista social com a militância em prol das populações indígenas e, posteriormente, em prol dos milhares de crianças excluídas da educação escolar, o que no seu entendimento, comprometia o presente delas e o futuro do país. Outra preocupação permanente em suas falas e reflexões tem relação com o ensino superior, tendo em vista que ele acreditava ser por meio deste que se poderia empreender uma renovação no modelo a formação das elites. Sua persistência em intervir no ensino superior expressa a preocupação com a urgência de formar quadros dirigentes mais afeitos às práticas democráticas, evitando a reprodução das práticas clientelistas, bem como o predomínio de concepções eivadas pelo sentimento de desprezo dirigido à população pobre, mascaradas pelo paternalismo das elites. 
Para tanto, ele ocupou todos os cargos que se lhes apresentaram, promoveu campanhas, escreveu livros, participou de programas na TV, ou seja, jamais poupou esforços para conseguir realizar os seus projetos de intervenção pública. Sua trajetória é multifacetada (Xavier, 2010 ), revelando o caráter múltiplo de um personagem singular, conforme observou Heymann (2012, pág.98). A autora chama atenção para o sentimento de urgência que o acossou e se aprofundou em razão da proximidade da morte, que ele experimentou desde a primeira internação hospitalar para tratamento do câncer no pulmão, em 1995. Em suas palavras, o medo de se saber vulnerável e a incerteza sobre o tempo de vida, apareceriam em vários de seus escritos - como Confissões e Migo - revelando o desejo de vencer o tempo e o esquecimento, permanecendo na memória das gerações futuras ( Heymann, 2012: 94).

Não por acaso, ele se preocupou tanto com preservação de sua memória, talvez imaginando que desse modo, suas ideias e projetos de intervenção na vida nacional convenceriam as novas gerações de sua importância, arregimentando adeptos para ajuda-lo na tarefa de passar o Brasil a limpo (Carta, 19917). Embora esta tenha sida uma preocupação que o acompanhou desde cedo e perdurou ao longo de sua vida, consideramos que foi como Senador que ele se empenhou de modo mais direto na tarefa de registrar de modo mais definitivo - tanto para o presente quanto para o futuro - a memória que ele desejava plasmar na juventude, bem como nas gerações vindouras. A contracapa da Edição 1991-2 da Revista é ilustrativa desta intenção, se apresentando nos seguintes termos.

Esta Carta quer ser um enlace de reflexão crítica de brasileiros lúcidos e insatisfeitos com a nossa realidade, tal qual ela é. Nosso propósito é passar o Brasil a limpo. Sabendo, porém, que para transformar é preciso, primeiro, entender, nos empenhamos em criar uma opinião melhor informada e mais combativa.

É possível perceber uma dupla intenção no trecho citado. Uma primeira, por meio da qual Darcy se apresenta como demiurgo da salvação nacional e uma segunda, que revela a crença na possibilidade de mudar o rumo da história do país e, mais que isso, a certeza de que aquele instrumento - a Revista - produziria esclarecimento, informação e, em resultado disso, novos quadros dispostos a participar do combate contra as elites preocupadas em açambarcar todo o poder e se apropriar de toda a riqueza em que possa pôr as mãos ( RIBEIRO,1994:7). Coerente com suas ambições, Darcy reproduz na Revista um discurso indignado no Senado, sobre as diversas crises que o povo brasileiro enfrentava na época, - em especial o escândalo que envolveu intrigas familiares e corrupção, levando ao impeachment do então Presidente Fernando Collor de 
Mello -, que na Revista Carta, recebe o sugestivo título

Salvemos a Nação Brasileira (RIBEIRO,1994:11).

A própria estrutura da Revista expressa essa crença na missão salvífica que ele toma para si, assim como o desejo de exercer uma ação pedagógica sobre os seus leitores, convidando-os por meio de suas falas, à reflexão e à apropriação de uma certa memória nacional. Assim, a abertura da Revista se faz com textos do próprio Darcy. Intitulada Falas e Escrituras, esta seção apresenta, em geral, um primeiro texto configurado como um pequeno Editorial, em que ele anuncia o tema e problematiza as questões que serão abordadas naquele número. Em seguida, são publicados discursos, planos e propostas de sua autoria, tais como os projetos do PEE (Carta 15,1995-2) e da UENF (Carta 10,1994-1). Este é também o espaço para divulgar seus projetos de lei, como o Projeto de Lei que resultou na promulgação da Lei 9394-1996, a Lei de Diretrizes e Bases da Educação Nacional Uma outra seção da Revista, intitulada Reflexões, publica artigos de jornais estrangeiros como o Le Monde Diplomatique, além de artigos assinados por acadêmicos e militantes de esquerda, incidindo sobre temas candentes do momento. A terceira seção constante desta Revista é a Seção de Memórias, na qual são republicados textos, Manifestos, entrevistas, que marcaram época e, em sua maioria, marcam a posição ou participação de Darcy Ribeiro no curso da história do Brasil. Retomaremos esse assunto adiante.

A Revista tem um caráter pedagógico, pois procura esclarecer o leitor a respeito do funcionamento da Câmara Alta, dos processos legislativos e questões nacionais várias, tais como a crise energética, a situação do negro, bem como noticia os projetos de lei em andamento. Em alguns números, o Editorial se dirige diretamente aos deputados, pedindo a atenção e o voto de aprovação deles para os projetos encaminhados no Senado.

Cabe registrar, por fim, o lugar da Seção Memórias no âmbito da Revista. Podemos afirmar que esta seção opera a construção de uma memória da formação nacional que tem como eixo a síntese entre as culturas indígenas, africanas e europeias, revitalizando o mito da fusão racial que constituiria o povo brasileiro como produto da mestiçagem, vista de um ponto de vista positivo. Mesmo assinalando com ênfase a sanha destruidora de culturas dos colonizadores europeus, Darcy conclui que o povo brasileiro, plasmado nos quadros culturais da civilização ocidental, expressa uma romanidade tardia, tropical e mestiça e acrescenta...

Uma nova Roma, melhor porque racialmente lavada em sangue índio, em sangue negro. Culturalmente plasmada pela fusão do saber e das noções de nossas três matrizes, iluminada pela experiência milenar dos índios para a vida no trópico, espiritualizada pelo senso musical e pela religiosidade do negro. (RIBEIRO,1993:14) 
Seria esta, uma primeira reflexão sobre a história da formação nacional, que aparece de modo recorrente em vários de seus escritos, falas e reflexões, ancorada na análise feita por um antropólogo que se dirige para o grande público. Uma segunda operação histórica, conjuga a memória de sua própria trajetória pública com os grandes marcos que erigem uma história da educação brasileira. Esta é construída com base em lutas sucessivas e ou concomitantes que inserem o educador Darcy Ribeiro, nos principais movimentos pela universalização do ensino e pela democratização do acesso a educação escolar. Tais operações são acompanhadas de textos nos quais Darcy exalta a sua filiação ao movimento da Escola Nova, atesta a sua participação nos momentos decisivos de processos que deflagraram definições legislativas, assim como de criação e renovação das instituições de ensino, sobretudo no âmbito do ensino superior, como já assinalamos anteriormente.

Isso explica a reedição do Manifesto dos Pioneiros da Educação Nova de 1932, considerado por Darcy, ainda na época da publicação da Revista, em 1995, nossa melhor proposição pragmática. Explica, também a publicação do posicionamento de diferentes intelectuais a respeito do Projeto da Universidade de Brasília, assim como todo o esforço que ele faz para demonstrar o acúmulo de experiência no âmbito da educação que ele logrou vivenciar ao longo de sua trajetória. Mas, como ele também procura deixar claro, a cada fala e em cada escrito, é o caráter democrático que urge imprimir à escola pública e ao ensino nela ministrado. Democratização que passa pelo reconhecimento positivo das características culturais do alunado, assim como pelo preparo permanente dos professores, com vistas ao cumprimento de uma rotina educativa competentemente planejada, entendida por Darcy como meio de acabar com o menor abandonado, que na sua percepção, só existia no Brasil. Para tanto, ele se singulariza, ao mesmo tempo em que se inclui na luta mais geral em oposição os falsos educadores prontos a reimplantar a escola pública corrente que não alfabetiza nem educa as crianças pobres (RIBEIRO:1995:15).

\section{A Democracia, o personagem e suas contradições}

Candido Alberto Gomes (2010) observa que as ações de Darcy foram marcadas pela pressa e, no caso do PEE, o autor considera que havia pressa em muitos aspectos. Em primeiro lugar, porque ele não gostava de gastar tempo com a burocracia, em segundo, porque a empreitada era grandiosa, quase inédita, e o mandato do Governo só durava quatro anos. Para contornar a burocracia, assim como para se desviar da oposição e dos reclames de participação na elaboração e implementação daquele Programa pelo Sindicato dos Professores da rede pública, Darcy recorreu 
à estratégia de estabelecer uma rede paralela e uma Secretária Extraordinária, responsável por implementar um Programa Especial de Educação. Como o próprio Darcy Ribeiro declarou, a ideia era agilizar o processo de implementação do PEE e garantir sua eficácia, livrando-o dos vícios e entraves cristalizados na rede ordinária de escolas. A esta ideia, somou-se a crença de que os bons frutos das escolas de tempo integral, automaticamente, provocariam um impacto modelar sobre o funcionamento das demais escolas.

Contudo, a própria genialidade de Darcy Ribeiro, associada ao seu ímpeto voluntarista e ao seu caráter carismático já constituíam por si só, um desestímulo ao desenvolvimento de processos mais rotineiros e previsíveis de institucionalização das inovações desejadas. Como observou Bomeny (2000:279) com base em Max Weber, não se rotiniza o extraordinário sem que o transformemos em algo previsível, reproduzível, o que vale dizer, não mais extraordinário. Somada ao caráter de excepcionalidade (especial e extraordinário) que o criador imprimiu ao seu Projeto, a pressa na contratação de profissionais para sustentarem as escolas de tempo integral, terceirizando o contrato da maioria deles e, desse modo, não lhes garantindo estabilidade como funcionários públicos em seus postos, abriu um flanco que permitiu que os sucessivos Governos interrompessem o PEE, utilizando os prédios de acordo com os interesses do momento, reduzindo o efetivo de profissionais ou convertendo muitos Cieps em escolas de meio turno. Por outro lado, é importante assinalar que o Projeto teve repercussão na esfera federal, com a adoção de projeto semelhante, lançado em 1991, prevendo a construção dos Centros Integrados de Apoio à Criança (CIACS), programa que incorporava alguns dos aspectos centrais da proposta do PEE. Posteriormente, já em 2007, o Ministério da Educação lançou o Programa Mais Educação, configurando uma versão aproximada do que se entenderia como ampliação da jornada escolar pela oferta flexível e diversificada de atividades educativas, expressando uma concepção, por assim dizer, barateada da ampliação da jornada escolar. ${ }^{6}$

Consideramos que, a despeito do sentimento de urgência agravado pela consciência de sua finitude, a pressa e obstinação para com a realização de seus projetos para o país são visíveis desde sua juventude, como podemos atestar no emaranhado de ações que ele empreendeu com vistas a viabilizar a construção da UnB, ${ }^{7}$ assim como na implantação e desenvolvimento do PEE e, ainda, no processo de tramitação da LDBEN de 1996.

As experiências das décadas de 1950-60 com o CBPE e a UnB, assim como as dos anos 1980-90, com o PEE e a LDBEN, forneceram a Darcy Ribeiro não só um repertório consistente de experiências de intervenção na organização do ensino em diferentes instâncias políticoadministrativas, assim como em diferentes níveis do sistema de educação formal, formulando e implementando planos, criando instituições e avaliando os seus impactos sociais. Esse capital 


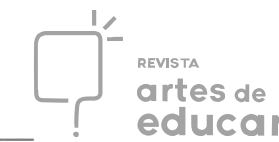

acumulado se expressou na letra da LDBN de 1996, assim como nas instituições de ensino que ele criou, apesar de poucas terem tido continuidade plena nas linhas em que ele as conformou.

Por outro lado, observando o processo de tramitação da LDBEN pelo prisma das ações dos agentes envolvidos, sobressaem os esforços sistemáticos do Fórum em aliança com os parlamentares progressistas e em luta contra as investidas dos grupos conservadores, representados pelos parlamentares afinados com os interesses dos empresários do ensino. Em meio a um campo de disputas entre grupos, entidades e partidos, surge a figura solitária de Darcy Ribeiro. Apresentando uma terceira via para solução dos conflitos que permearam o processo de tramitação da LDBEN, Darcy Ribeiro acenaria para o Governo a possibilidade de arbitrar entre os dois grupos majoritários, em disputa, com uma terceira proposta apresentada por ele, apoiada na credibilidade política e intelectual que ele carreara para si.

Irrompendo em meio à radicalização dos embates entre os grupos privatistas e os defensores da reserva de verbas públicas para a educação pública, a conduta do Senador Darcy Ribeiro poderia ser interpretada, em sua carga simbólica, como a intervenção de um agente que assumiu para si o papel heróico de mediador do interminável conflito entre o mundo dos princípios e o mundo dos interesses (Girardet:1987) . Retirando deste argumento heroico a legitimidade de seu feito, Darcy Ribeiro justificaria a imprevista abreviação do processo de tramitação da lei, contida em seu gesto. Promovendo rupturas e atropelando o percurso de tramitação da LDBEN, a aprovação da Lei Darcy Ribeiro, em seu processo e conteúdo, sinalizam uma espécie de revelador ideológico, o reflexo de um sistema de valores ou de um tipo de mentalidade que - para o bem ou para o mal - encontra lugar em nossa sociedade.

\section{Referências}

BOMENY, Helena Maria Bousquet. Darcy Ribeiro: Sociologia de um indisciplinado. Belo Horizonte: Editora da UFMG, 2001.

DICIONÁRIO HISTÓRICO BIOGRÁFICO BRASILEIRO - CPDOC/FGV (verbetes Darcy Ribeiro e LDB)

DICIONÁRIO DE EDUCADORES BRASILEIROS - Editora UFRJ (verbete Darcy Ribeiro). DISCURSO.

GIRARDET, Raul. Mitos e mitologias políticas. Cia das Letras São Paulo, 1987.

GOMES, Candido Alberto . MEC: Coleção Grandes Educadores. MEC-Fundação Joaquim Nabuco, Editora Massangana, 2010. 
HEYMANN, Luciana. O lugar do Arquivo: a construção do legado de Darcy Ribeiro. Rio de Janeiro, Contracapa, 2012.

RIBEIRO, Darcy. UNB: invenção e descaminho. São Paulo, Editora Perspectiva, 1970. . Sobre o Óbvio. Rio de Janeiro, Editora Guanabara, 1986. . Confissões. São Paulo, Cia das Letras, 1997. . A Educação e a Política. Revista Carta 2, Senado Federal, 1995. . Salvemos a nação brasileira. Revista Carta 4, Senado Federal, 1945. .Discurso de posse de Darcy Ribeiro na Academia Brasileira de Letras. Revista

Carta 7, Senado Federal, 1993

XAVIER, Libania. O Brasil como laboratório: educação e ciências sociais no projeto do CBPEInep-MEC (1950-1960). Bragança Paulista, EDUSF, 1999. . A pesquisa do CBPE em revista. In BRANDÃO, Z. e MENDONÇA, A. W. Uma tradição esquecida: Por que não lemos Anísio Teixeira? Rio de Janeiro, Editora Forma e Ação, 2 edição (pp. 103-176), 2008.

\footnotetext{
${ }^{1}$ A noção de redemocratização ou transição democrática deve levar em consideração as ponderações de Avritzer (2000) que problematiza o termo, propondo que se ampliem os marcos nos quais a democracia é pensada para além dos processos de continuidade e ruptura, de modo a perceber a transição de um sistema democrático-elitista instável para um sistema democrático mais institucionalizado e participativo no qual a sociedade civil e os atores políticos democráticos desempenham papel de relevo.

${ }^{2} \mathrm{O}$ documento enunciava as declarações em simples afirmações agrupadas nos subtítulos Sou Contra: a educação elitista e antipopular; o analfabetismo da maioria dos brasileiros; a multiplicação de escolas privadas e ruins e
}

Sou a Favor: de uma escola primária popular e séria; do uso de recursos públicos em escolas públicas, da educação para o desenvolvimento econômico e social. Cf: Xavier, 1999.

${ }^{3}$ No Brasil, ele liderou a elaboração e implantação de modelos inovadores de educação superior com a criação da Universidade de Brasília - UnB (1961) e, após o seu retorno definitivo ao país, com a criação da Universidade do Norte Fluminense - UENF (1993), na cidade de Campos dos Goytacazes (RJ).

${ }^{4}$ Com um modelo inovador, onde os departamentos dariam lugar a laboratórios temáticos e multidisciplinares, o projeto da então chamada Universidade do Terceiro Milênio previa, também, a articulação com os Laboratórios de Engenharia e Exploração do Petróleo e de Meteorologia a serem implantados no município vizinho de Macaé, bem como a missão de implantar e incrementar um Parque de Alta Tecnologia do Norte Fluminense. A criação da UENF viabilizou o acesso ao ensino superior aos jovens da região, antes restrito àqueles que tivessem condições de fixar residência no Rio de Janeiro ou em Niterói.

${ }^{5} \mathrm{Cf}$ Ver a respeito, o texto assinado por Darcy Ribeiro e publicado na Revista Carta, intitulado Salvemos a Nação brasileira

${ }^{6}$ O Programa Mais Educação, criado pela Portaria n 17/2007, visa ampliar as atividades educativas nas escolas públicas, prevendo ações socioeducativas no contra turno escolar para alunos do ensino fundamental, agrupadas em macro campos como acompanhamento pedagógico, meio ambiente, esporte e lazer, direitos humanos, cultura e artes, promoção da saúde.

Cf http://portal.mec.gov.br/index.php?Itemid=586id=12372option=com contentview=article 20/07/2017, $16 \mathrm{~h}$.

${ }^{7}$ As negociações para carrear apoio do Governo e da Ordem dos Dominicanos (que obteve uma recomendação do Papa relativa ao projeto da UnB) levaram a que Darcy incluísse no projeto desta Universidade um Instituto de Teologia Católica (apesar de ter defendido a educação pública e laica ao longo de sua trajetória). Em outros momentos, ele 
adotou estratégias pouco convencionais. Por exemplo, em abril de 1960, a revista Senhor publicava a Carta de Pero Vaz de Caminha, adaptada por Darcy ao cenário brasileiro dos anos 60. Nesta, ele propagandeava os feitos do governo JK, apresentando a nova capital como ponto de partida e meta de chegada do processo de construção do país do futuro - um Brasil, moderno, economicamente dinâmico e democrático. Em tom brincalhão, o texto concluía com um pedido a El Rei, em nome do povo de Brasília, convencendo-o da necessidade de uma universidade capaz de articular uma base cultural própria. 